\title{
CHEMICAL AND EXPERIMENTAL ANALYSIS OF FUMIGATION PROCESS TO REDUCE EMISSION WITHOUT AFFECTING THE PERFORMANCE OF AN ENGINE
}

\author{
S. Sendilvelan ${ }^{1 *}$ and K. Bhaskar ${ }^{2}$ \\ ${ }^{1}$ Department of Mechanical Engineering, Dr. M.G.R. Educational and Research Institute, \\ University, Chennai-600095, (Tamilnadu) India \\ ${ }^{2}$ Department of Automobile Engineering, Rajalakshmi Engineering College, Thandalam, \\ Chennai-602105, (Tamilnadu) India \\ *E-mail : sendilvelan.mech@drmgrdu.ac.in
}

\begin{abstract}
Diesel engines have been widely used for better efficiency and low emissions, but diesel engine produces more smoke, particulate matter and oxides of nitrogen and reducing all these emissions simultaneously is not possible as on today due to trade of between oxides of nitrogen and smoke. Engines emission can be decreased by employing fumigation. Using fumigation process emission composition can be reduced when compared to normal operation. In this work an attempt has been made to reduce oxides of nitrogen, hydrocarbon and carbon monoxide using methanol fuel in the combustion chamber. The chemical behaviors and reactions of methanol over hydrocarbons also analyzed. A single cylinder four stroke, 5hp, direct injection, engine test rig was used for experiment purpose. From the experimental analysis, it was found that alcoholic fuels can effectively be used in diesel engines with methanol fumigation using EFI kit that normally operates at high power outputs. The result shows that brake thermal efficiency is slightly decreased when compared without modification at all flow rates.

Keywords: Fumigation Process, Methanol Structure, Performance, Emission Control, Diesel Engine
\end{abstract}

(C) RASĀYAN. All rights reserved

\section{INTRODUCTION}

Direct injection (DI) diesel engines are a better choice as prime movers in many applications, it has become compulsory to reduce emission due very strict regulations. For this purpose, many attempts are ongoing to improve the emission of diesel engines without affecting the performance. The increase in need for petroleum fuels and also the fast depletion has forced the researchers for investigating new methods to reduce emission and improve the performance of the prime movers. Due to the depletion of petroleum product and the continuous increase in cost, it is the urgent need to develop alternative fuels especially to diesel oil ${ }^{1}$. Diesel engines have the advantages of high thermal efficiency lower emission of $\mathrm{CO}$ and HC. Among various renewable and oxygenated fuels methanol, ethanol and butanol shows considerable improvement in the emission reduction. Because these oxygenated fuels can be blended directly to with diesel and can be used in prime movers.

The oxygenated fuels reduce the soot since the oxygen atoms in its structure ${ }^{2-4}$. The oxygen availability in the fuel gives smokeless combustion in diesel engines. Several scholars have investigated the methanol in diesel engines over the past twenty years. At low temperature, the methanol miscibility is very poor and it has less heating values also it has the major disadvantage of undesirable lubricating properties. Due to the above disadvantages has to be rectified by implementing minor changes in the fuel systems ${ }^{6}$. The literature survey shows that Methanol, Ethanol and Butanol have the required property to reduce emissions compared to diesel. This study has focused on using methanol as an oxygenated blend component in diesel fuel using fumigation methods to solve the above problem without any engine modifications, and the influence of Chemical reaction over emission has been reported. Fumigation is a process of injecting the fuel into the air intake system in diesel engine. This mixture of fuel and air creates

Rasayan J. Chem., 10(1), 111-116 (2017)

http://dx.doi.org/10.7324/RJC.2017.1011564 
homogeneous form which helps increasing the burning capacity of the engine. Chunde yao et al conducted experiments using diesel and methanol compound and reported reduction of soot and oxides of nitrogen besides slight increase in carbon monoxide and hydrocarbon ${ }^{7}$. Zhang et al investigated application of fumigation methanol and a diesel oxidation catalyst for reducing emissions ${ }^{8}$. Wang et al studied the operating range and characteristics using methanol fumigated engine ${ }^{9}$. Kwon reported that the ethanol blends increases the ignition delay with increase in ethanol content ${ }^{10}$. Alcohol may be fumigated with air gives better results for emissions, combustion and performance improvements. These systems should be attached with the present manufacturer equipment may be retrofit on to the existing engines. For variable speed engines, fumigation rate should be adjusted by the original equipment manufacturer $(\mathrm{OEM})^{11,12}$. Advanced automatic control unit monitor the mixing of methanol fumigation rate for better combustion. The fumigation reduces oxides of nitrogen effectively also soot reduction is commendable. Fumigating fuel should have the boiling point temperature must between $50^{\circ} \mathrm{C}-80^{\circ} \mathrm{C}$ and more number of bonds and also have large number of carbon chain ${ }^{13}$. These oxygenated fuels does not blend with diesel effectively, because of that it is mixed with air in the intake systems ${ }^{14}$. Carefully selecting the rate of ethanol and mixing with air fumigation rate may be increased for maximum benefit. By this method methanol(methyl alcohols), ketones like isobutyl methyl ketene, methyl ethyl ketene are used as fumigation fuels ${ }^{15}$.

\section{EXPERIMENTAL}

Methanol, high stoichiometric ratio and ratio of hydrogen to carbon when compared with diesel show more benefit for the reduction of soot and particulate emissions. The methanol also called as methyl alcohol, wood alcohol, wood naphtha or wood spirits, is a chemical name and its chemical formula is $\mathrm{CH}_{3} \mathrm{OH}$. The methanol can burn in air after burning it produces carbon dioxide and water. A methanol flame is colorless, but creating some safety problem with flames. Methanol may be produced from the distillation process of wood. In recent development it also produced synthetically in a furnace by reformation ${ }^{16}$. Methane reacts with stream at a pressure of 1 to $2 \mathrm{MPa}$ and at high temperatures produces carbon monoxide and hydrogen. It is also called reforming process. It is an endothermic process. Methane oxidized partially with oxygen molecules and produce syngas. This reaction is exothermic. When the endothermic and exothermic reactions combined together is called thermal reforming. The carbon monoxide and steam reacts together to form carbon dioxide and hydrogen.

The carbon monoxide and hydrogen with catalyst such as mixture of copper, zinc oxide and alumina, generates methanol. It is clear that in the case of methane one mole of carbon monoxide reacts with three moles of hydrogen, while the methanol using 2 moles of hydrogen. The molecular structure of methanol is shown in Figure 1. To alcohol supplement in to the intake air with the use of simple carburetor, which is used to fumigate the mixture as well as vaporize the alcohol into the intake air. The maid disadvantage is it needs additional carburetor and an injector, along with a separate fuel tank, lines and control ${ }^{14}$.

Diesel fuel cannot be replaced by alcohols due to the requirement of mixture combine together to form a homogeneous solution, which is very difficult. Different techniques emerged to lower alcohols like methanol and ethanol duel fuel ${ }^{15}$. These techniques are alcohol-diesel fuel blend, dual injection and alcohol fumigation ${ }^{17}$. Most of these studies are focused on to calculate the design of the carburetor for fumigation ${ }^{18}$. In this work the performance and emissions are studied by adapting a microprocessor controlled electronic pump with injector to control the flow rate. Experiments were conducted for $0.8 \mathrm{gm} / \mathrm{min}$ fumigation rates of methanol and the results were compared with diesel.

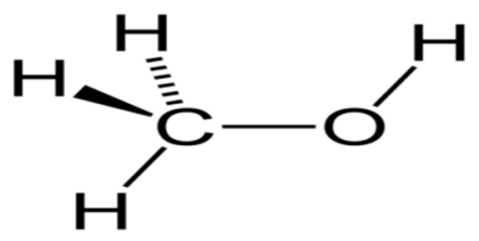

Fig. - 1: Molecular Structure of Methanol 
RASĀYAN J. Chem.

Vol. 10 | No. 1 |111-116 | January - March | 2017

Table-1: Chemical Properties of Methanol

\begin{tabular}{c|c}
\hline Formula & $\mathrm{CH}_{3} \mathrm{OH}$ \\
\hline Molar weight $(\mathrm{g} / \mathrm{mol})$ & 32.04 \\
\hline Color, State & Colorless and Liquid state \\
\hline Density $\left(\mathrm{g} / \mathrm{cm}^{3}\right.$, liquid $)$ & 0.7918 \\
\hline Melting point $(176 \mathrm{~K})$ & $-97^{\circ} \mathrm{C}$ \\
\hline Boiling point $(337.8 \mathrm{~K})$ & $64.7^{\circ} \mathrm{C}$ \\
\hline Solubility & Fully miscible in water \\
\hline Acidity $(\mathrm{pKa})$ & $\sim 15.5$ \\
\hline Viscosity at $20^{\circ} \mathrm{C}$ & $0.59 \mathrm{mPa} . \mathrm{s}$ \\
\hline
\end{tabular}

\section{Brake Thermal Efficiency Variations}

\section{RESULTS AND DISCUSSION}

The above figure shows the variation of the brake thermal efficiency when methanol fuel is charged in to the engine. At $25 \%$ and $50 \%$ load, brake thermal efficiency decreases with increase in methanol flow rate. This may be due to the lower temperature of the compressed charge and dilution of the charge at low loads. At higher load, the temperature of the compressed charge is high, which results in better combustion of the fuel.

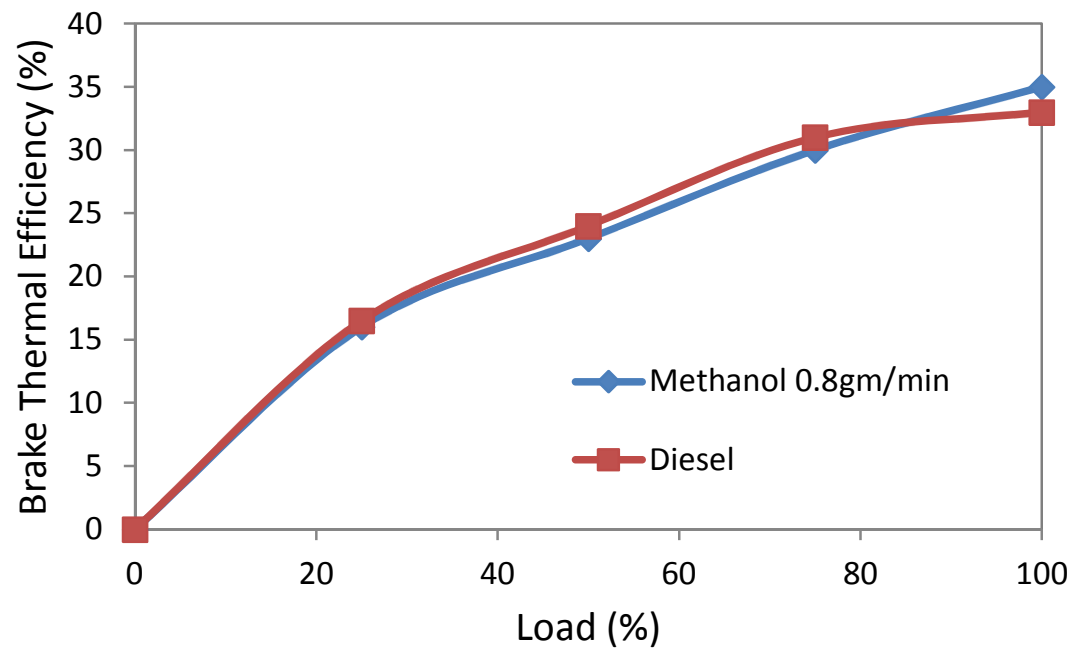

Fig. - 2: Variation of Brake Thermal Efficiency with Load

\section{Oxides of Nitrogen Emission Variations}

Figure 3 compares the emission rates of NOx with and without methanol fumigation. The NOx is normally produced due to the high temperature in combustion chamber and that of exhaust gases. By supplying methanol at $0.8 \mathrm{gm} / \mathrm{min}$ flow rate the NOx emissions are reduced considerably. At rated power output the NOx value was $496 \mathrm{ppm}$ using methanol flow rate of $0.8 \mathrm{gm} / \mathrm{min}$ compared with the diesel with NOx value of $795 \mathrm{ppm}$. The percentage decrease in NOx was $37.61 \%$. The flow rate of methanol with $0.8 \mathrm{gm} / \mathrm{min}$ was optimum (Table-2).

\section{Hydrocarbon and Carbon monoxide Emission Variations}

Figure-4 and 5 shows the comparison between methanol fumigation and diesel combustion for the emissions HC and CO. It is observed in the case of hydrocarbons due to the presence of oxygen and carbon atoms the emission of carbon monoxide and Hydrocarbons is high at a flow rate of $0.8 \mathrm{gm} / \mathrm{min}$. 
RASĀYAN J. Chem.

Vol. 10 | No. 1 |111-116 | January - March | 2017

The HC values are high at no load and part load conditions, but decreases sharply at full load conditions and reached almost same value as diesel.

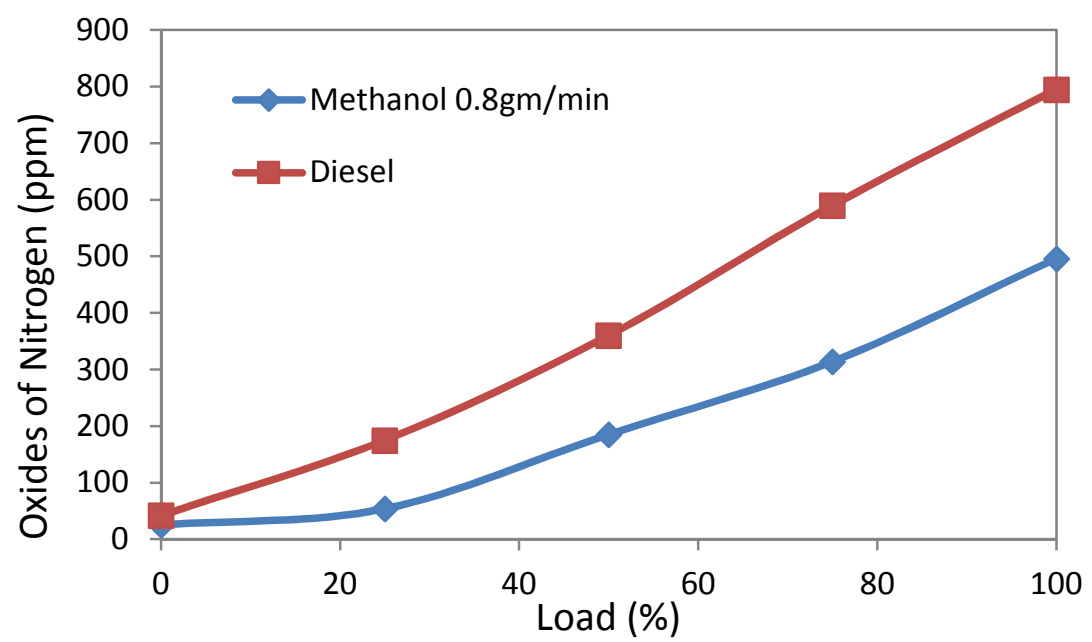

Fig. - 3: Variation of Oxides of Nitrogen with Load

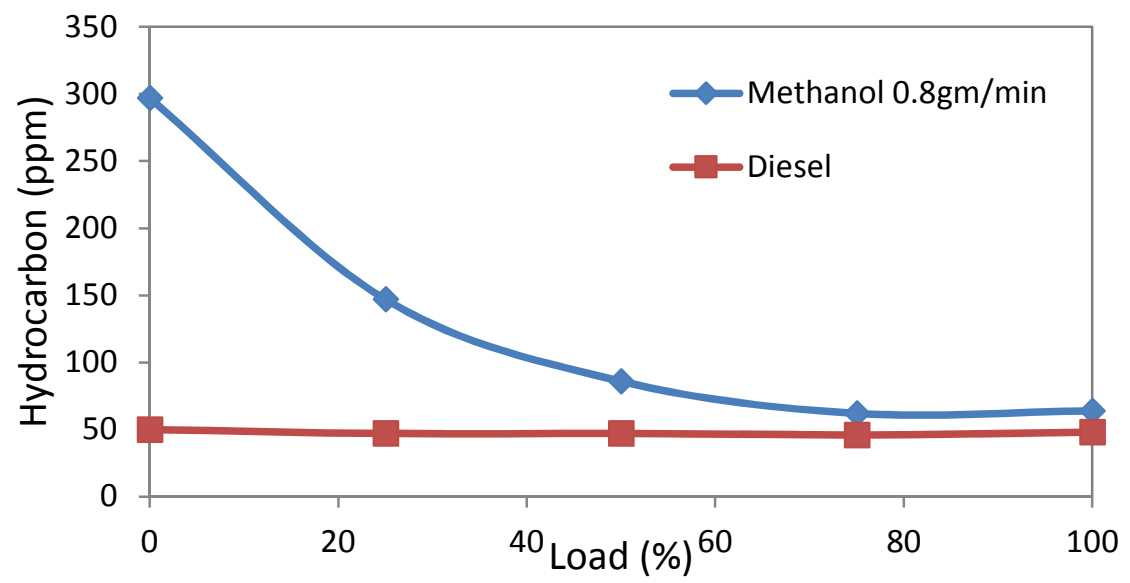

Fig. - 4: Variation of Hydrocarbon with Load

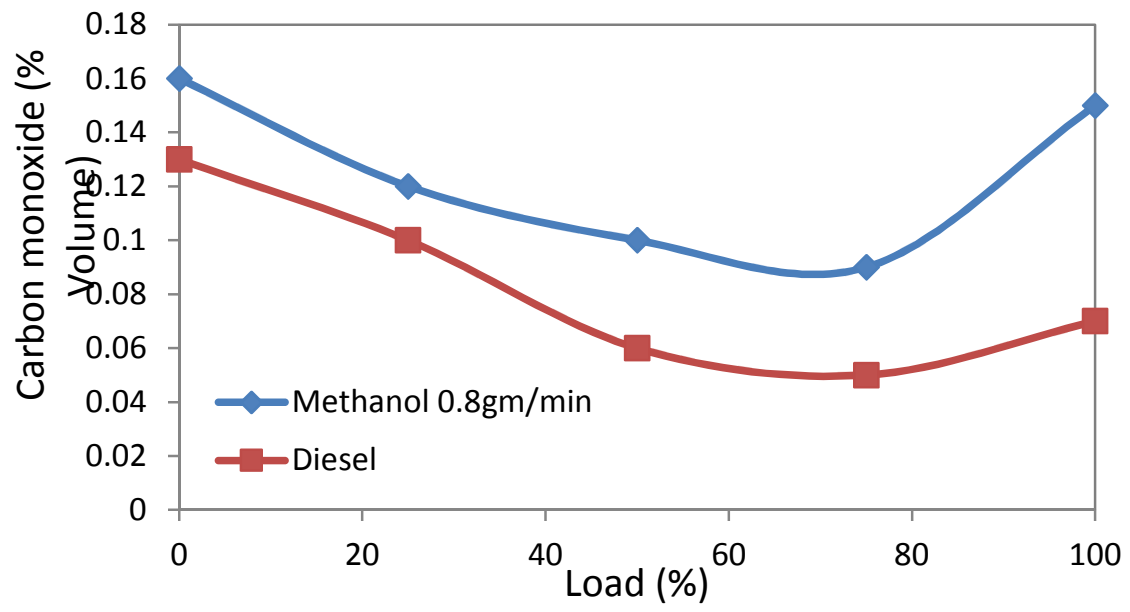

Fig.-5: Variation of Carbon monoxide with Load 
It is observed in the case of carbon monoxide emission is high at a flow rate of $0.8 \mathrm{gm} / \mathrm{min}$ compared with diesel. The $\mathrm{CO}$ values are high at no load and part load conditions, but increases sharply at full load conditions and reached $0.15 \%$ by volume. At no load the value of $\mathrm{CO}$ was $0.16 \%$ by volume. While in the case of diesel the value of $\mathrm{CO}$ at no load condition it was $0.13 \%$ by volume. At full load condition the value of $\mathrm{CO}$ was $0.07 \%$ by volume. But with the different flow rate of methanol $0.8 \mathrm{gm} / \mathrm{min}$ show less $\mathrm{CO}$ emission compared with other flow rates. From the above investigations, the NOx was reduced with methanol and $\mathrm{CO}, \mathrm{HC}$ emission increased with methanol. The methanol flow was optimized, which $0.8 \mathrm{gm} / \mathrm{min}$.

Similar trend follows for the flow rate of $1.0 \mathrm{gm} / \mathrm{min}$ and the values at rated power output are given in the form of Table-2. Table shows clearly $0.8 \mathrm{gm} / \mathrm{min}$ of methanol flow rate having maximum advantages compared with the other flow rates. The brake thermal efficiency reduced slightly compared with lower flow rates. The objective of this work is to reduce the emissions of oxides of nitrogen, hydrocarbon and carbon monoxide, $0.8 \mathrm{gm} / \mathrm{min}$ have been suggested for optimum flow rate.

Table-2: Variation of Methanol Flow Rate and Its Performance, Emission Values

\begin{tabular}{c|c|c|c|c}
\hline $\begin{array}{c}\text { Methanol Flow } \\
\text { Rate }(\mathrm{gm} / \mathrm{min})\end{array}$ & $\begin{array}{c}\text { Brake Thermal } \\
\text { Efficiency }(\%)\end{array}$ & $\begin{array}{c}\text { Oxides of Nitrogen } \\
(\mathrm{ppm})\end{array}$ & $\begin{array}{c}\text { Hydrocarbon } \\
(\mathrm{ppm})\end{array}$ & $\begin{array}{c}\text { Carbon monoxide } \\
(\% \text { by Volume })\end{array}$ \\
\hline 0.2 & 34.94 & 527 & 72 & 0.12 \\
\hline 0.4 & 34.84 & 512 & 72 & 0.12 \\
\hline 0.6 & 34.74 & 504 & 70 & 0.12 \\
\hline 0.8 & 34.64 & 494 & 69 & 0.11 \\
\hline 1.0 & 34.43 & 498 & 70 & 0.13 \\
\hline
\end{tabular}

\section{CONCLUSION}

From the above analysis, it is found that alcoholic fuels can effectively be used in diesel engines with methanol fumigation using EFI kit in an engine that normally operates at high power outputs. The result shows that brake thermal efficiency is slightly decreased when compared without modification at all flow rates. The NOx emission decreased considerably from $527 \mathrm{ppm}$ to $494 \mathrm{ppm}$ at a flow rate of $0.8 \mathrm{gm} / \mathrm{min}$ of methanol. The hydrocarbons emission decreased from $72 \mathrm{ppm}$ to $69 \mathrm{ppm}$, carbon monoxide emissions decreased from $0.12 \%$ by volume to $0.11 \%$ by volume and brake thermal efficiency decreased from $34.94 \%$ to 34.645 . Based on the experimental investigation methanol flow rate of $0.8 \mathrm{gm} / \mathrm{min}$ show optimum emission reduction due to the presence of carbon and oxygen atoms.

\section{REFERENCES}

1. H.K. Rashedul, H.H. Masjuki, M.A. Kalam, A.M. Ashraful, S.M. Ashrafur Rahman, S.A. Shahir, Energy Conversion and Management, 88, 348 (2014).

2. G. Yanfeng, L. Shenghua, G. Hejun, H. Tiegang, Z. Longbao, Applied Thermal Engineering 27 (1), 202 (2007).

3. R. Murali Manohar, M. Prabhahar, S. Sendilvelan, European Journal of Scientific Research, 76 (3), 327 (2012).

4. S. Sendilvelan, K. Jeyachandran, K. Bhaskar, In American Society of Mechanical Engineers, Internal Combustion Engine Division (Publication) ICE; 2001, 36 (5), (2001).

5. H. Omidvarborna, A. Kumar, D.S. Kim, Renewable and Sustainable Energy Reviews, 48, 635 (2015).

6. D. Li, Z. Huang, X.C. Lu, W. Zhang, J. Yang, Renewable Energy, 30 (6), 967 (2005).

7. C. Yao, C.S. Cheung, C. Cheng, Y. Wang, T.L. Chan, S.C. Lee, Energy Conversion and Management, 49(6), 1696 (2008).

8. Z.H. Zhang, C.S. Cheung, T.L. Chan, C.D. Yao, Science of The Total Environment, 407(15), 4497 (2009)

9. Q. Wang, L. Wei, W. Pan, C. Yao, Fuel, 140, 164 (2015.)

10. S.I. Kwon, M. Arai, H. Hiroyasu, Journal of the marine engineering society in japan, 24(5), 124 (1989). 
RASĀYAN J. Chem.

Vol. 10 | No. 1 |111-116 | January - March | 2017

11. N. Miyamoto, H. Ogawa, M. Nabi, International Journal of Engine Research, 1(1),71 (2000).

12. C. Sundar Raj, S. Arul, S. Sendilvelan, C.G. Saravanan, Energy Sources, Part A: Recovery, Utilization and Environmental Effects, 32(17), 1603 (2010).

13. C.D. Rakopoulos, K.A. Antonopoulos, D.C. Rakopoulos, Energy, 32(10), 1791 (2007).

14. Z. Şahin, O. Durgun, O.N. Aksu, Energy Conversion and Management, 103, 778 (2015).

15. P. Satgé De Caro, Z. Mouloungui, G. Vaitilingom, J.C. Berge, Fuel, 80(4), 565 (2001).

16. L. Zhu, C.S. Cheung, W.G. Zhang, Z. Huang, Fuel, 90(5), 1743 (2011).

17. T. Husberg, S. Gjirja, I. Denbratt, J. Engström, SAE Technical Paper, 724, (2004).

18. D.B. Hulwan, S.V. Joshi, Applied Energy, 88(12), 5042 (2011).

19. N.Raman,D.Sathiya Narayanan, Rasayan J.Chem., 1(4), 828 (2008).

20. S.Kalaiselvan, K.Anitha, P.Shanthi, P.S.Syed Shabudeen, S.Karthikeyan, Rasayan J.Chem., 7(4), 333 (2014).

[RJC-1564/2017] 